\title{
Plant Based Dairy Analogues: An Emerging Food
}

\author{
Deep N Yadav*, Sangita Bansal, Arvind K Jaiswal and Ranjeet Singh \\ ICAR-Central Institute of Post-Harvest Engineering \& Technology, India
}

Submission: March 01, 2016; Published: August 23, 2017

"Corresponding author: Deep N Yadav, ICAR-Central Institute of Post-Harvest Engineering \& Technology, Ludhiana-141004, Punjab, India, Email: dnyadav1977@yahoo.co.in

\begin{abstract}
At present, for medical reasons, significant amount of consumers opt for plant based milk substitutes for various medical reasons or as a lifestyle choice. Medical reasons include lactose intolerance as well as milk protein allergies. Plant milk substitutes also serve as a more affordable option. Technologically, plant milk substitutes are suspensions of dissolved and disintegrated plant material in water, resembling cow's milk in appearance. They are manufactured by extracting the plant material in water, separating the liquid and formulating the final product. Homogenization and thermal treatments are necessary to improve the suspension and microbial stabilities of commercial products that can be consumed as such or be further processed into fermented dairy type products. Groundnut and soybean are two major raw materials used for preparation of plant based milk. The nutritional properties depend on the plant source, processing and fortification. If formulated into palatable and nutritionally adequate products, plant based substitutes can offer a sustainable alternative to dairy products.
\end{abstract}

\section{Introduction}

Plant based milk substitutes are water extracts of legumes, oil seeds, cereals or pseudocereals that resemble animal milk in appearance and consistency. There is a wide variety of traditional plant based beverages around the world, for example "tigernut milk" in Spain; Sikhye, a beverage made of cooked rice, malt extract and sugar in Korea; Boza, a fermented drink made of wheat, rye, millet and maize consumed in Bulgaria, Albania, Turkey and Romania; Bushera, a fermented sorghum or millet malt based beverage from Uganda, and traditional soy milk originating from China. The most widely consumed plant based milk substitute is soy milk. The first commercially successful product was launched in Hong Kong in 1940 and the market grew rapidly during the seventies and early eighties in Asia after the development of technologies for large scale production of mild flavoured soy milk [1]. The demand for soy milk in the Western world was initiated by consumers intolerant to cow's milk or lactose [2]. Soy products are still dominating the market in the Western world, but the emerging of alternative products from other plant sources such as coconut, oat, peanut and almond have decreased its share. Overall, the dairy alternative market is still growing. According to an estimate, 15\% of European consumers avoid dairy products for a variety of reasons, including medical reasons such as lactose intolerance (LI), cow's milk allergy (CMA), cholesterol issues and phenylketonuria, as well as lifestyle choices like a vegetarian/vegan diet or concerns about growth hormone or antibiotic residues in cow's milk [3]. The main treatment for LI is the avoidance of lactose containing foods and replacing milk and dairy products with lactose free dairy or dairy free alternatives. Functional food market is dominated by dairy based probiotic products mainly yoghurt. There is need to develop dairy alternatives due to allergenic milk proteins, lactose and high cholesterol content $[3,4]$.

Total world production of groundnut in 2012-13 is about $37.2 \mathrm{mt}$. It is major oilseed crop in India accounting for $45 \%$ of oilseed area and $55 \%$ of oilseed production. India is rated as the second largest producer of groundnut in the world with annual production of over 5-6mt. China, India, Nigeria, USA and Myanmar are the major groundnut growing countries. Groundnut contains on an average 40-45 per cent oil and 23-25 per cent protein and is a rich source of calcium, iron and vitamin B complex like thiamine, riboflavin, niacin and vitamin A. In developing countries, it is mainly used for oil extraction and it's by product is utilized for animal feed purposes. Animal milk, in India at any rate, has a venerated place as a food for both children and adults. A milk-like beverage, or a re-constitutable powder from which to generate it by adding water, represents an acceptable way of furnishing proteins and other nutrients to all age groups, often at reasonable cost. Plant based milk substitutes may serve as a 
boon for the countries where the supply of milk is inadequate. Groundnut and soybean are two major raw materials used for preparation of milk like products [5].

\section{Process}

Plant based milk substitutes are colloidal suspensions or emulsions consisting of dissolved and disintegrated plant constituents. They are prepared traditionally by grinding the raw material into slurry and straining it to remove coarse particles. The general outline of a modern industrial scale process is essentially the same for different plant materials as it is soaked and wet milled to extract the milk constituents, or alternatively the raw material is dry milled and soluble material is extracted in aqueous media. The insoluble material is separated by filtering or decanting followed by addition of desired ingredients for acceptable product formulation. Most commonly used ingredients include sweetner, flavourings, stabilizers, colouring agents etc. Since, plant based dairy analogue forms suspension type solution, hence to improve suspension and microbial stability; homogenization and pasteurization/UHT treatment are necessary. These extracts can also be spray dried to produce more stable powder, which can be further reconstituted to get a desired product [6].

\section{Pre-treatments}

Raw material pre-treatments include dehulling, soaking and blanching [7]. Blanching is required to inactivate trypsin inhibitors and lipoxygenase that would produce off-flavours in soy milk and peanut milk $[8,9]$. Roasting of the raw material enhances the aroma and flavour of the final product, but heating decreases the protein solubility and extraction yield $[10,11]$.

\section{Extraction}

The extraction step has a profound effect on the composition of the resulting product. To increase the yield of the process, the efficiency of this step may be improved by increasing the $\mathrm{pH}$ with bicarbonate or $\mathrm{NaOH}$, elevated temperatures or the use of enzymes. Alkaline $\mathrm{pH}$ during extraction increases the protein extractability. A higher extraction temperature increases the extractability of fat, but the denaturation of proteins decreases their solubility and yield [11]. However, the extraction of protein can be enhanced by hydrolyzing the protein using plant, animal or microbial based enzymes [12]. Observed increase in protein content of peanut and soy milk after hydrolyzing with papain and crude enzyme extract of Pestulotiopsis westerdijkii. In addition to proteolytic enzymes, a mixture of amyloglucosidase and a cellulase cocktail has been shown to increase the carbohydrate recovery of peanut milk [12,13]. Eriksen [13] used a variety of enzymes in soy milk extraction and found that the highest protein and total solids yield was attained using a neutral or alkaline proteinases at their optimum $\mathrm{pH}$. In addition to increasing the extraction yield, proteolytic enzymes improve the suspension stability [14]. Treatment with cellulase after homogenization has been reported to decrease the particle size and yield a more stable suspension [15].

\section{Separation}

After extraction, coarse particles are removed from the slurry by filtration, decanting or centrifugation. When using raw materials high in fat, such as peanuts, the excess fat can be removed using a separator as in dairy processing. The separated cream like product can be heat treated to obtain oil or can be used as such in ice-cream formulations and bakery industry. Thus, the process can be economized. Removal of excess oil/fat from the extract also facilitates to formulate a more stable beverage.

\section{Product formulation}

Other ingredients can be added to the product base after the removal of insoluble coarse material. These include vitamins, minerals sweeteners, flavourings, salt, oils and stabilizers. Suspension stability of plant based milk substitutes is a major concern, which can be overcome by using hydrocolloids/ emulsifiers. Mono- and diglycerides, glyceryl monostearate, guar gum and carrageenan can be effectively used for stabilizing peanut and soymilk. Though the plant based milk analogues resembles in appearance and consistency to the animal milk but, they significantly differ in nutritional quality as well as bioavailability of nutrients. Hence fortification of these types of products is necessary to ensure the nutritional quality. The nutrients used must be bioavailable and sufficiently stable, and not cause excessive changes in product quality. The challenge in mineral enrichment is the reactivity of metal ions with other food components, and the use of sequestrates such as citric acid may thus be necessary (Zhang et al., 2007a). Some mineral sources used in plant based milk substitutes include ferric ammonium citrate and ferric pyrophosphate as iron sources and tricalcium phosphate and calcium carbonate as calcium sources $[16,17]$.

\section{Stability}

Plant based milk substitutes contain insoluble particles, such as protein, starch, fibre and other cellular materials. Due to density difference, these particles get settle down, making the product unstable. The suspension stability can be increased by decreasing the particle size or by using hydrocolloids and emulsifiers [18]. Many plant based milk substitutes coagulate during thermal treatment due to unfolding of proteins. Unfolding results in exposure of non-polar amino acids to water, which enhances protein-protein interactions and results in aggregation and sedimentation or gelling [19]. The heat stability of proteins depends on the $\mathrm{pH}$, ionic strength and the presence of other compounds such as minerals and carbohydrates [20]. Homogenization in the conventional dairy processing pressure range (20MPa) improves the stability of plant based milk substitutes by disrupting aggregates and lipid droplets and thus decreasing the particle size distribution [21]. Ultra high pressure homogenization (UHPH) of soy milk at 200-300MPa reduces the 
particle sizes intensely and improves the stability compared to conventionally processed products. A higher homogenization temperature has been reported to increase the stability of peanut milk [10]. In soy milk, heat denaturation of proteins is required for suspension stability.

\section{Shelf life}

Commercial plant based milk substitutes are pasteurized or UHT treated to extend the shelf life. Pasteurization is generally carried out at below $100{ }^{\circ} \mathrm{C}$, which destroys pathogenic microorganisms. [22] treated peanut beverage for 4 and $20 \mathrm{~s}$ at 137 ${ }^{\circ} \mathrm{C}$ and observed that the longer treatment time decreases suspension stability, and enhances taste and acceptability. Pulsed electric fields have also been suggested to extend the microbial shelf life at commercial scale [23]. Other non-thermal processes such as ultraviolet sterilization, high pressure throttling, high pressure processing and ultra-high pressure homogenization (UHPH) have been explored as methods of soy milk preservation by various researchers [24-27].

\section{Fermented products}

Fermentation with lactic acid bacteria improves the sensory, nutritional properties and shelf life. Plant based milk substitutes can be fermented to produce dairy free yoghurt type products while rendering the raw material into a more palatable form $[4,5]$. The levels of hexanal responsible for the undesired nutty flavour in peanut milk can be efficiently reduced with fermentation [28]. Fermentation of soy milk reduced the amount of flatulence inducing oligosaccharides [29]. Additives such as carboxymethyl cellulose, coagulants (calcium citrate), milk powder and gelatin have been used to enhance the texture and reduce syneresis in the final product $[28,30]$.

\section{Nutritional quality}

Plant based milk substitutes are often perceived as healthy. In reality the nutritional properties vary greatly, as they depend strongly on the raw material, processing, fortification and the presence of other ingredients such as sweeteners and oil. Milks produced using legumes other than soy, such as peanut and cowpea can have protein content as high as $4 \%$ [31]. Plant milk substitutes are low in saturated fats and most products have calorific value comparable to skim milk. Plant proteins are generally of a lower nutritional quality compared to animal derived proteins due to limiting amino acids (lysine in cereals, methionine in legumes) and poor digestibility. The nutritional value of proteins depends mainly on the amino acid composition, physiological utilization and absorption. Population groups with low animal milk intakes often have deficiency of dietary calcium, iodine, vitamin B12 and riboflavin. To combat these shortcomings, plant based milk substitutes can be fortified with calcium and vitamins, mainly B12, B2, D and E. However, consumer awareness is important as many of the existing plant based milk substitutes are not fortified.

\section{Acceptability}

The demand for plant milk substitutes is increasing; however the unwillingness of the mainstream consumer to try unfamiliar foods that are perceived as unappealing may be a limiting factor. Many modern day soy and peanut milks and related products may have an improved sensory quality, but the product group carries a stigma because of early less appealing products on the market. Legume milks tend to possess "beany" and "painty" off-flavours originating from lipoxygenase activity [11]. The presence and intensity of the "beany" flavour depends on processing and storage conditions of soy milks and varieties [32,33]. Another problem is chalky mouthfeel due to large insoluble particles [18]. The acceptance of peanut milk has been shown to depend on the colour, mouthfeel, nutty flavour and similarity to cow's milk $[6,8]$. Taste is the most important purchase criteria of foods, and the information about a good and/or familiar taste increase the willingness to try an unfamiliar food. Possible health benefits are also an important criteria and health information may increase both the willingness to try and the perceived liking of a food.

\section{Future prospects}

Plant based milk substitutes have a reputation of "health foods" but the products on the market vary remarkably in their nutritional profiles, some having very low protein and mineral contents. If these products are to be portrayed as substitutes for cow's milk, protein content and quality as well as fortification has to be considered by manufacturers. Attention should be brought to the possible ways of improving the nutritional properties by processing means i.e. the use of enzymes and the selection of raw materials based on their protein quality. Reconstitution approach may also allow a more efficient extraction of protein from the material and the formulation of higher protein products. This would however increase the costs and also the environmental impact of the products. More knowledge is required to overcome the mineral fortification related stability issues.

\section{References}

1. Chen S (1989) Preparation of fluid soymilk. In: Proceedings of the World Congress on Vegetable protein Utilization in Human Foods and Animal Feedstuffs pp. 341-351.

2. Patisaul HB, Jefferson W (2010) The pros and cons of phytoestrogens. Front Neuroendocrinol 31(4): 400-419.

3. Jago D (2011) Free from foods - Mintel report. Free From Allergy and Intolerance FDIN seminar. Daventry, UK, England.

4. Bansal S, Mangal M, SharmaSK, Yadav DN, Gupta RK (2016) Optimization of process conditions for developing yoghurt like probiotic product from peanut. LWT- Food Science and Technology 73: 6-12.

5. Sangita B, Manisha M, Sharma SK, Yadav DN, Gupta RK (2016) Optimization of fermentation conditions for probiotic soy yoghurt using response surface methodology. Journal of Food Processing and Preservation doi:10.1111/jfpp.12415.

6. Diarra K, Nong ZG, Jie C (2005) Peanut milk and peanut milk based products production: A review. Crit Rev Food Sci Nutr 45(5): 405-423. 
7. Debruyne I (2006) Soy base extract: soymilk and dairy alternatives. In: Riaz MN (Edt.), Soy applications in foods, Taylor \& Francis, Boca Raton, Florida, USA, pp. 111-134.

8. Jain P, Yadav DN, Rajput H, Bhatt DK (2011) Effect of pressure blanching on sensory an dproximate composition of peanut milk. J Food Sci Technol 50(3): 605-608.

9. Giri S, Mangaraj S (2012) Processing Influences on Composition and Quality Attributes of Soymilk and its Powder. Food Eng Rev 4(3): 149164.

10. Hinds MJ, Beuchat LR, Chinnan MS (1997a) Properties of a thermalprocessed beverage prepared from roasted partially defatted peanuts. International Journal of Food Science and Technology 32(3): 203-211.

11. Chauahn GS, Yadav DN, Agrawal K (2003) Development of beany flavour free soymilk and soy paneer. Processed Food Industry 13-22.

12. Rustom I, Lopez-LMH, Nair BM (1993) Extraction of peanut solids with watereffect of the process and enzymatic hydrolysis. LWT-Food Sci Technol 26: 72-75.

13. Eriksen S (1983) Application of enzymes in soy milk production to improve yield. J Food Sci 48: 445-447.

14. Rustom I, Lopez-LM, Nair BM (1991) A study of factors affecting extraction of peanut (Arachis hypogaea L.) solids with water. Food Chem 42: 153-165.

15. Rosenthal A, Deliza R, Cabral L, Cabral LC, Farias CAA, et al. (2003) Effect of enzymatic treatment and filtration on sensory characteristics and physical stability of soymilk. Food Control 14 : 187-192.

16. Zhang H, Önning G, Öste R, Gramatkovski E, Hulthen L (2007) Improved iron bioavailability in an oat-based beverage: the combined effect of citric acid addition, dephytinization and iron supplementation. Eur J Nutr 46(2): 95-102.

17. Zhao Y, Martin BR, Weaver CM (2005) Calcium bioavailability of calcium carbonate fortified soymilk is equivalent to cow's milk in young women. J Nutr 135(10): 2379-2382.

18. Durand A, Franks G, Hosken R (2003) Particle sizes and stability of UHT bovine, cereal and grain milks. Food Hydrocoll 17: 671-678.

19. Phillips L, Whitehead D, Kinsella J (1994) Chemical nature of proteins and polypeptides. In: Structure-Function Properties of Food Proteins, Academic Press: San Diego, CA, USA, pp. 3-23.

20. McSweeney SL, Mulvihill DM, O Callaghan DM (2004) The influence of $\mathrm{pH}$ on the heat-induced aggregation of model milk protein ingredient systems and model infant formula emulsions stabilized by milk protein ingredients. Food Hydrocolloid. 18: 109-125.
21. Malaki NA, Tosh S, Poysa V, Woodrow L, Corredig M (2008) Physicochemical characterization of soymilk after step-wise centrifugation. Food Res Int 41(3): 286-294.

22. Rustom I, Lopez-LM, Nair B (1996) Nutritional, sensory and physicochemical properties of peanut beverage sterilized under two different UHT conditions. Food Chem 56: 45-53.

23. Cortés C, Esteve M, Frıgola A, Torregrosa F (2005) Quality characteristics of horchata (a Spanish vegetable beverage) treated with pulsed electric fields during shelf-life. Food Chem 91: 319-325.

24. Bandla S, Choudhary R, Watson DG, Haddock J (2011) UV-C treatment of soymilk in coiled tube UV reactors for inactivation of Escherichia coli W1485 and Bacillus cereus endospores. LWT-Food Sci Technol 46: 7176.

25. Cruz N, Capellas M, Hernandez M, Trujillo A, Guamis B, et al. (2007) Ultra high pressure homogenization of soymilk: Microbiological, physicochemical and microstructural characteristics. Food Res Int 40: 725-732.

26. Smith K, Mendonca A, Jung S (2009) Impact of high-pressure processing on microbial shelf-life and protein stability of refrigerated soymilk. Food Microbiol 26(8): 794-800.

27. Sharma V, Singh RK, Toledo RT (2009) Microbial inactivation kinetics in soymilk during continuous flow high-pressure throttling. J Food Sci 74(6): M268-M275.

28. Yadav DN, Singh KK, Bhowmik SN, Patil RT (2010) Development of peanut milk-based fermented curd. Int J Food Sci Technol 54: 26502658.

29. Yadav DN, Chauahn GS, Kumbhar BK (2008) Optimization of processing variables for the preparation of soy-fortified curd (Dahi) using response surface methodology. Journal Food Sci Technol 45(2): 127-132.

30. Cheng Y, Thompson L, Brittin H (2006) Sogurt, a Yogurt-like Soybean Product: Development and Properties. J Food Sci 55: 1178-1179.

31. Tano-DK, Asiamah K, Sakyi-DE, Budu A (2005) Effect of malt enzyme treatment on the nutritional and physicochemical characteristics of cowpea-peanut milk. In: Proceedings of the 1st international edible legume conference/IV $\mathrm{IV}^{\text {th }}$ world cowpea congress, Durban, South Africa.

32. Chambers E, Jenkins A, McGuire BH (2006) Flavor properties of plain soymilk. J Sens Stud 21: 165-179.

33. Yadav DN, Chauahn GS, Bajpai A, Sharma P, Chauhan OP (2003) Quality evaluation of curd prepared from milk-soymilk blends. Journal Food Sci Technol 40(4): 403-405.

This work is licensed under Creative

DOI: 10.19080/ARTOAJ.2017.10.555781

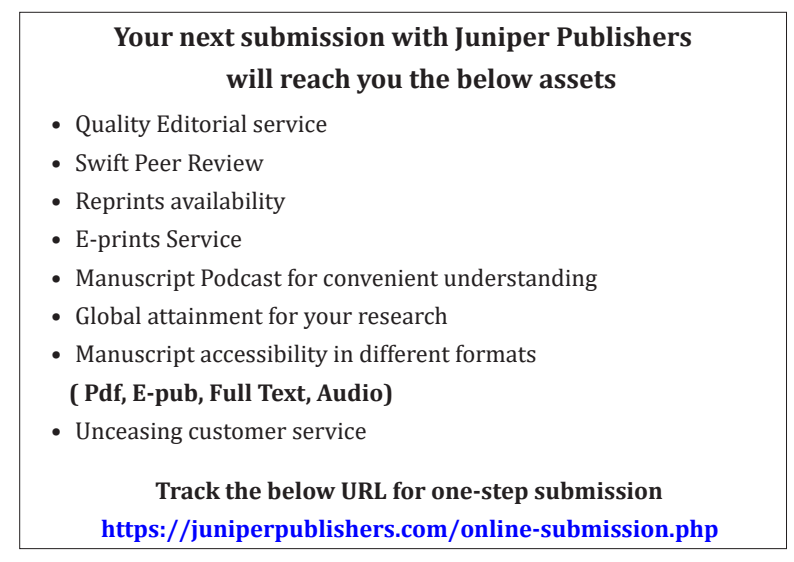

Your next submission with Juniper Publishers will reach you the below assets 